\title{
3 \\ A Proposal for a New Research Direction
}

\section{Roger C. Sutherland and Gary R. Minton}

There is a growing need in the stormwater community for better BMP selection and design methods. The continuing impact of urban stormwater on surface water quality has also driven the need for more accurate modeling of stormwater pollution. Both stormwater program managers and site designers need appropriate methods and tools that can explicitly address the inherent uncertainties in stormwater quantities and qualities and Best Management Practice (BMP) performance. With scientifically based easy to use tools like the one proposed in this chapter, stormwater program managers would be able to identify appropriate BMP selection and design criteria having the highest likelihood of solving specific water quality problems. With this proposed tool, site designers would be able to satisfy specified criteria with the most cost effective BMP selection and design available.

\subsection{Physically Based Models Are Needed}

Physically based urban stormwater quality models are needed to provide a much better understanding of the pollutant concentration data that already has been collected. These models can focus attention on what specific needs exist for additional data. Physically based models are mathematical programs designed to simulate the actual physical processes that are directly related to the desired output of the model itself. Physically based models

Sutherland, R. and G.R. Minton. 2009. "A Proposal for a New Research Direction." Journal of Water Management Modeling R235-03. doi: 10.14796/JWMM.R235-03.

(C) CHI 2009 www.chijournal.org ISSN: 2292-6062 (Formerly in Conceptual Modeling of Urban Water Systems. ISBN: 978-0-9808853-2-3) 
frequently utilize empirical algorithms within their frameworks to describe relationships between variables that are considered relevant to the process being simulated. However, it's the interactions between the processes, if properly formulated, which provide knowledge of a problem that rarely can be achieved through a simple statistical analysis of the data itself.

For example, one desired output of an urban stormwater quality model could be the storm-by-storm event mean concentration (EMC) of total suspended solids (TSS) in the runoff from a small urban site of interest. A physically based model would attempt to separately simulate the various important processes and interactions that are thought to ultimately lead to the desired result. In this example, it is widely believed that both a pollutant accumulation process and a pollutant washoff process ultimately produce the TSS concentrations observed in urban runoff. So, a physically based TSS stormwater quality model would separately simulate the accumulation of particulate material on the site of interest including its important physical characteristics that could significantly affect washoff like particle size distribution and the location of the accumulation on the site (e.g. street surface, parking lot, rooftop, etc). The accumulation algorithm would likely be nonlinear with time and may include variables like traffic volume or pavement type and condition.

A physically based washoff component should include algorithms to convert observed rainfall into time-varying runoff flow taking losses into consideration like infiltration and depression storage. As an alternative, the time-varying runoff flow could be computed from an established model that includes these physical processes like SWMM or HSPF. The washoff component should have a hydraulic algorithm that estimates the timevarying depth and velocity of the flow along the upland flow paths where the particulate material is accumulated. These hydraulic characteristics establish the time-varying available capacity of the runoff flow to transport the available supply of sediment. And finally, a physically based washofff component would contain appropriate sediment transport equations capable of estimating the time-varying amount of accumulated material actually being transported by the urban flow. These washoff algorithms would likely include both suspended load and bedload transport formulations And to be accurate, the washoff component would require an understanding of the erratic time-varying sediment supply verse transport capacity behavior govern by specific particle size groupings that bed armoring regulates even in shallow flow conditions such as gutter flow or sheet flow across parking lots.

The physically based stormwater quality model described in this example could then generate time-varying estimates of both runoff flow (i.e. 
hydrograph) and transported sediment mass for each storm event. To compute the storm-by-storm TSS EMCs (which was the desired object) one would simply divide the total sediment mass washed off by the total runoff volume for each storm event. An added benefit of using a physically based model is its ability to analyze alternative scenarios. Our example model could be used to determine the increase in TSS EMCs from increased impervious cover due to urbanization or increased traffic volume. One could also analyze alternative time periods through the use of historic rainfall data. In our example, readily available rainfall data could be used to simulate hundreds or even thousands of TSS EMCs from the site of interest. Results from statistical analyses of the simulated TSS data could then be compared to those from the more limited observed data sets to improve our knowledge of the uncertainty of TSS EMCs on a site of interest.

\subsection{Focus on Source Areas}

Typical pollutant loading models are based on various land use types: single and multi-family residential, commercial, industrial, freeways, and open space. Unfortunately, this format is not particularly useful, as it is not tied directly to the specific BMPs under consideration and likely to be implemented. An alternative format could be based on pollutant source areas like streets, parking lots, roofs, landscaped areas of various descriptions, and other activity types that relate directly to pollutant sources like construction sites or gas stations. A focus on source areas allows a direct tie to BMPs and various Low Impact Development (LID) treatments or practices as noted below:

- Streets: BMPs include pavement cleaning, sump cleaning, catch basin filters or screens. LIDs include porous pavements and rain gardens. Loadings differ by street type such as highway or freeway, arterial, commercial (whether CBD or shopping center), residential collectors; pavement type; pavement age; slope, etc.

- Parking lots: BMPs and LIDs similar to streets. Loadings vary by parking lot type or activity (e.g. high volume retail to light commercial employee lot).

- Landscaped areas: BMPs include education programs on fertilizer and pesticide use. LIDs include amended soils, swales and rain gardens. 
- Roofs: BMPs include downspout disconnect or treatment. LIDs include green roofs, blue roofs and cisterns. Loadings differ by type and age of roof materials, atmospheric deposition, etc.

- Construction sites: Erosion control BMPs. Loadings vary by soil type and land slope.

- Other: Developments that generate special loadings such as gas stations, hobby farms, and particular industries with outside activities.

A source area approach to stormwater monitoring and modeling isn't new since a few researchers have already keyed on this idea and have promoted its use for decades. Perhaps the best example is Pitt and Voorhees' SLAMM program which keys on source areas and has been around for almost twenty years (Pitt and Voorhees, 1995). Unfortunately, source areas are rarely used in current practice where the focus is on the type of land use and not the source areas that comprise it.

Using a source area approach, one can identify the total area within a defined watershed that relate to the same sources. For large watersheds (e.g. tens of thousands of acres), the location of the source areas within the watershed is important and should be subdivided into smaller subbasins to better understand the actual pollutant transport. The primary value of this source area approach is that it recognizes some watersheds contain already developed areas. In many situations, the watershed is completely developed; therefore, the focus should be and will be on nonstructural BMPs, along with some LIDs and treatment devices implemented through redevelopment.

\subsection{Land Use Cannot Predict Stormwater Quality}

Maestre and Pitt (2007) recently combined nationwide stormwater quality data from four major stormwater databases: NURP, USGS, International BMP Database, and NSQD. The combined database contained approximately 10,000 individual stormwater events from 594 sampling locations representing sixteen different land use categories spread throughout all nine of USEPA's defined rain zones. Their analysis found that, within a given rain zone, the variability between sampling locations for several land use categories is greater than the variability between the land uses themselves. According to their results, it is expected that $5-20 \%$ of the sites located in the same USEPA rain zone and land use category will have median concentrations that are significantly different than the remaining sites in the group. In other 
words, traditional land use classifications are poor indicators of actual stormwater quality.

Based on Maestre and Pitt's conclusions, it is obvious that using the "simple method" approach to estimate stormwater pollutant loadings will likely result in poor predictions at both the individual site and watershed scales. For clarification, "The Simple Method" involves assigning an invariant constant concentration for a specified pollutant of interest and for a particular land use type. Many of the most popular pollutant load generation models currently used today like PLOAD and almost all spreadsheet type models use this "simple method" approach. The selected median or mean concentrations are typically based on local or regional data such as those made available by Maestre and Pitt (2007). At the watershed scale, these estimated pollutant loads for each contributing land use type, are usually obtained by assigning invariant runoff coefficients to each land use type, and then combining the pollutant loads using GIS techniques to provide estimates at some downstream point in the watershed.

There are a few advanced "simple method" approaches that assign a statistical distribution of pollutant concentrations to each land use type. This distribution is usually based on a single-variate statistical analysis of observed data. Unfortunately, the results from this approach are likely flawed for particulates (see Section 3.5 for further discussion on this point). Although this advanced simple method technique does add the illusion of uncertainty in the generation of land use based stormwater pollutant loads and concentrations, it still possesses one major flaw. There is no direct explicit relationship between the specific physical characteristics and anthropogenic activities occurring on the source areas within the land use of interest and the resulting pollutant load and concentration response. If any change in the underlying causes of pollution occurs, there remains no change in the pollutant load or concentration distribution assumed for that type of land use. So this results in no linkage between the underlying site characteristics and activities and its actual stormwater quality response. This is always true when using a simple method approach; no matter how advanced the method appears to be.

\subsection{Factors that can Predict Stormwater Quality}

Maestre and Pitt's conclusions were not unexpected for those who have developed and used physically based deterministic stormwater quality models for decades (Sutherland and Jelen, 1996; Pitt, 1997). The important 
things that affect stormwater quality are: (i) the characteristics of the precipitation the site or watershed receives, (ii) the physical characteristics of the site or watershed, and (iii) the anthropogenic activities that occur on each of the source areas within the site or watershed. Source areas will provide varying amounts and qualities of stormwater runoff dependent upon these things (Waschbusch et al., 1999; Pitt et al., 2005).

Studies have shown for decades that urban impervious surfaces constructed to transport or store vehicles seem to generate the greatest pollutant mass loadings (i.e. highways, streets, driveways and parking lots) compared to those with no automotive activities. Schueler, formerly with the Center for Watershed Protection, refers to these source areas as "habitat for cars." The profession has known for over 30 years that the magnitude of accumulated pollutants found on these "habitats for cars" is directly related to the daily volume of cars using a specific roadway or parking lot (Shaheen, 1975; Sutherland et al., 2006). If the research goal is to develop a real understanding between the built environment and the resulting quality of stormwater runoff impacting downstream receiving waters, ignoring the relationships between activities on urban source areas and the accumulated pollutants that are readily available for transport would be inappropriate.

Unfortunately, the focus cannot simply be just streets, parking lots, and highways. Other impervious surfaces like roofs, sidewalks and pathways; and pervious areas like lawns, landscaping and vacant lots can also affect both receiving water quantity and quality. Sutherland and Jelen (1996) showed that pervious source areas adjacent to directly connected streets and parking lots can contribute significant amounts of sediments and associated pollutants to observed street dirt accumulations. This behavior has been defined as "wet weather accumulation". Other researchers have referred to it as wet weather washon. Sutherland and Jelen (1996) also showed that once these behaviors are adequately accounted for using a continuous accumulation function, then sediment and pollutant washoff could be accurately modeled storm by storm, one season to another, year after year.

Only a pollutant load generation model that is based on the physical characteristics of a site and the anthropogenic activities occurring on a site that is formulated to account for the complex source area interactions (i.e. like wet weather washon) can produce an accurate population of stormwater pollutant loads and concentrations expected to occur over a historical record of observed rainfall characteristics. Only then can these model output responses be directly linked to actual changes in any of the underlying factors like physical characteristics, anthropogenic activities and rainfall itself. 


\subsection{Is the Existing Quality Dataset Flawed?}

A large body of stormwater quality data has been collected over the past 40 years. It is not possible, given the large amount of data and several hundred publications, to summarize what these data are "telling us" regarding physical, chemical and bacterial constituents of stormwater. Chapter 2 of Minton's book Stormwater Treatment: Biological, Chemical and Engineering Principles (Minton, 2002) provides an introduction and overview of the subject. One might conclude that today there is little need to collect "end-of-pipe" stormwater data, inasmuch as there is so much data of this type. Certainly, it means that the stormwater community needs to be more selective. Others would argue that we should essentially begin anew in collecting data. Why? There are two reasons.

First, there is evidence that all of our past monitoring is biased and should be "tossed out". Why biased? Because the withdrawal water velocities of older automatic samplers limited pickup capabilities with regard to particle size. Silt and sand particles larger than 100 to $200 \mu \mathrm{m}$ have been rarely sampled. Somewhat larger sizes of organic particles and clays having lower specific gravities have likely been collected.

The second reason for a bias in current stormwater quality data is related to the standard laboratory procedures for total suspended solids (TSS) testing that have generally been used. Samples collected in the field must be split into aliquots for analysis. Rapid hand mixing and pouring fails to properly move larger material that may have been captured. And, lab test sub-sampling procedures failed to pick up these particles. Newer procedures (e.g. churn splitters, separate analysis of larger material by prescreening, full sample rather than sub-sample analysis, etc.) have likely reduced these laboratory procedures biases.

A 1998 study of runoff from an interstate highway in Cincinnati, Ohio used gravimetric-based sampling techniques that relied on gravity for the sample collection not automatic samplers. The study also filtered and analyzed the entire volumes of discrete samples obtained throughout each sampled runoff event. The study concluded that $20 \%$ by mass of the particulate material transported in the runoff ranged from 600 to $1000 \mu \mathrm{m}$ and $30 \%$ from 1000 to $10,000 \mu \mathrm{m}$ (Sansalone, et al., 1998). Recent discrete runoff sampling of eight storms captured from an elevated section of I-10 in Baton Rouge, Louisiana used both gravimetric sampling techniques and whole effluent analyses. The study found particles in transport that ranged from 1 to 24,500 $\mu \mathrm{m}$ in size (Kim and Sansalone, 2008). 
If we are to believe the results of Sansalone's research, then one must conclude that the concentrations of sediments and their associated pollutants found in runoff from highway pavements have been routinely understated. Metals, phosphorus, petroleum and related hydrocarbons, and pesticides, are all hydrophobic and, therefore, sorb to these larger particles. Sansalone and Cristina (2004) found that more than $60 \%$ of the particulate-bound metal mass (i.e. $\mathrm{Cd}, \mathrm{Cu}, \mathrm{Pb}$, and $\mathrm{Zn}$ ) was associated with particles greater than $250 \mu \mathrm{m}$.

The view for over two decades has been that at least one-half the sediment in stormwater is silts and clay, the rest sand size. Data, collected in a manner that avoids automatic sampler limitations, suggests sand is the dominant size at least in runoff from highway pavements. The question that should be asked and answered is whether particles greater than 100 to $200 \mu \mathrm{m}$ are dominant in runoff from other source areas.

Others have argued that we may have had a bias in the opposite direction. Concentrations, and therefore loadings, may now be overstated to the extent that we have tended to sample larger storms (e.g. 0.5 in. $(13 \mathrm{~mm})$ or more in depth). Most runoff occurs from much smaller storms. In Portland, Oregon, for example, approximately $70 \%$ of the cumulative annual runoff volume occurs from rainfall events of less than 0.5 in. Smaller storms have lower rainfall intensities, resulting in lower overland and street gutter flow velocities and, consequently, lower pollutant washoff concentrations. Transported particles are likely smaller in these storms because of low gutter velocities. Hence, the bias of older automatic samplers and poor analysis techniques may have been counterbalanced by the failure to recognize the dominance of the smaller storms.

The authors believe that the research direction that is now needed is the development of stormwater quality models that can focus on source areas, are physically based and can accurately simulate the particle size distribution of sediments found in runoff on a storm-by-storm basis, one season to another, year after year.

\subsection{Future Value of Proposed Research}

Due to the controversy surrounding the measurement of sediments in transport and the dominance of small storms, there are concerns regarding the validity and value of the national stormwater quality datasets. Abandoning these data would be foolish considering the time, effort and money spent gathering this information. Instead, these databases could be 
used along with physically based stormwater quality models with proven sediment transport capabilities to help explain and potentially expand these incomplete observations.

Physically based explicit models can be used to understand and, if necessary, expand the flawed TSS data on a site-by-site basis. This can be done by comparing historic measured TSS concentrations to those computed TSS concentrations obtained from only the finer fraction (i.e. less than 100 to $200 \mu \mathrm{m}$ ) of the model's simulated washoff. This is why the model needs to be able to provide accurate particulate washoff estimates and TSS concentrations throughout a runoff event for various size ranges of transported sediments.

Model parameters can then be adjusted to more closely match these comparisons. The resulting "calibrated" model will then simulate pollutant washoff from long traces of historic rainfall. These simulations will then include reasonable estimates from the model of all sediment sizes being transported by the stormwater, including those finer fractions being observed by existing collection techniques. The comparison of the statistics from the simulated washoff data to that from the original flawed dataset will help us understand the significance of the sediment transport issues at each site of interest on a case-by-case basis. These case studies would allow one to enhance and expand the historic dataset and gain valuable insights into the potential effectiveness of various BMPs.

\subsection{Scientifically Based Explicit Approach Is Needed}

The new research direction being proposed, keys on the words scientifically based and explicit. Webster's New Collegiate Dictionary defines scientific as agreeing with, or conducted or prepared strictly according to, the principles and practice of exact science. The same dictionary defines science as a branch of study concerned with observation and classification of facts. And finally, explicit is defined as clearly developed with all of its elements apparent. To be explicit and scientifically based, the stormwater management tool that we propose for development should be clear with all of its elements apparent and their relationships to each other well understood. And it should agree with the stormwater quality observations that have been made and the facts that have been discovered to date.

To be explicit and scientifically based, the stormwater management tool must be able to simulate long-term continuous hydrographs rather than single-event peaks or just small storms. At the highly desired site scale, the 
tool should appropriately consider shallow subsurface flow or interflow, which has been shown to be important in the accurate estimation of small area discharges. At the watershed scale, the tool should be able to simulate both interflow and base flow which can provide accurate estimates of continuous stream flows or receiving water discharges.

To be explicit and scientifically based, the stormwater management tool must be able to simulate the flow reductions associated with site specific low impact development (LID) practices for both new development and retrofit. It must be able to simulate the appropriate buildup and washoff from each of the significant source areas found throughout the urban landscape like streets, parking lots, rooftops, driveways, vegetated areas and areas of special activities like construction sites or gas stations.

To be explicit and scientifically based, the stormwater management tool must be able to simulate the day-to-day and storm-to-storm interaction of and pollutant removals from BMPs that are specifically designed for each source area. The tool must be able to simulate the complex interaction of stormwater sediments and other pollutants being transported from one source area to another. For example, wet weather washon from adjacent landscaped or paved area impacts the sediment accumulations on and eventual stormwater quality of runoff from streets or parking lots located down slope.

Since land use alone has been shown to be a poor indicator of stormwater quality, the stormwater management tool should focus on source areas within each land use. Source areas relate directly to the generation of pollutants and the application of both LIDs and BMPs.

Effective stormwater management also requires both water quality and quantity controls for minimizing watershed hydrology. Studies of urbanized watersheds repeatedly show that streams are adversely impacted by increased wet weather flows and altered dry season base flows. Stormwater conveyed via pipes to streams and wetlands increases runoff volume and rate while eliminating infiltration and groundwater recharge. Consequently, channels are scoured deeper and wider, reducing channel diversity and lowering in-channel water depth needed for aquatic species survival and riparian vegetation. Preserving historic watershed hydrology is critical to the long-term health, viability and quality of receiving waters. The tool we envisioned must include effective stormwater quantity mitigation design options like LID techniques, which will in turn provide significant water quality benefits. 


\subsection{Flow Duration Design Model (FDDM)}

From several years of working for various Pacific Northwest clients, Pacific Water Resources, Inc. (PWR) has developed a powerful program that looks and feels like an EXCEL spreadsheet, but it actually executes explicit and scientifically based algorithms written in $\mathrm{C}++$ code and linked with .dll files. Called the Flow Duration Design Model (FDDM), it provides the user with a flow duration response from a specific site using a continuous historic rainfall record. The user simply inputs the actual acreage of defined land cover categories that are proposed within the development site. FDDM includes six different LID practices along with extended detention. The user must input the specific design characteristics of each LID or the extended detention facility being proposed. Multiple facilities can be specified and they can act in series or parallel. FDDM then explicitly simulates the flow duration response from each of these land cover categories or source areas specified for the site. This continuous simulation that typically spans some 50 years or more of historic rainfall is quickly accomplished by the use of previously developed runoff time series (RTS) assigned to each of the available land cover or source area categories. FDDM then explicitly models the flow interaction, routing, evaporation, infiltration and storage associated with the user specified LIDs and extended detention throughout the site. FDDM is an explicit model in that any change in any of the design characteristics of any specified LID or detention would create a change in the flow duration response from that modeled facility and ultimately the site.

The runoff time series that FDDM currently uses are based on a continuous hydrologic watershed model known as HSPF. Various land cover categories or source areas within the watersheds of interest where FDDM would be applied are calibrated to available streamflow gauges to produce continuous hourly time series of runoff flow. Each calibrated time series corresponds to a land cover category or source area contained within the model. The user simply selects the subbasin where the site is located and the appropriate runoff time series related to land cover and underlying soil infiltration are automatically assigned. Creation of these pre-simulated runoff time series allows FDDM's adaptation to microclimate effects caused by mountains or terrain changes, for example.

With FDDM, local jurisdictions can vary their watershed management strategies at the subbasin level. While model calculations are site based, the value of aquatic resources typically varies greatly across a watershed. The ability to set targeted imperviousness at the subbasin level recognizes that high quality resources within a watershed may require greater protection 
than severely degraded resources. It also enables jurisdictions to balance economic needs against environmental stewardship in accordance with community values. This tool operates quickly and efficiently using an Excel spreadsheet interface (see Figure 3.1).

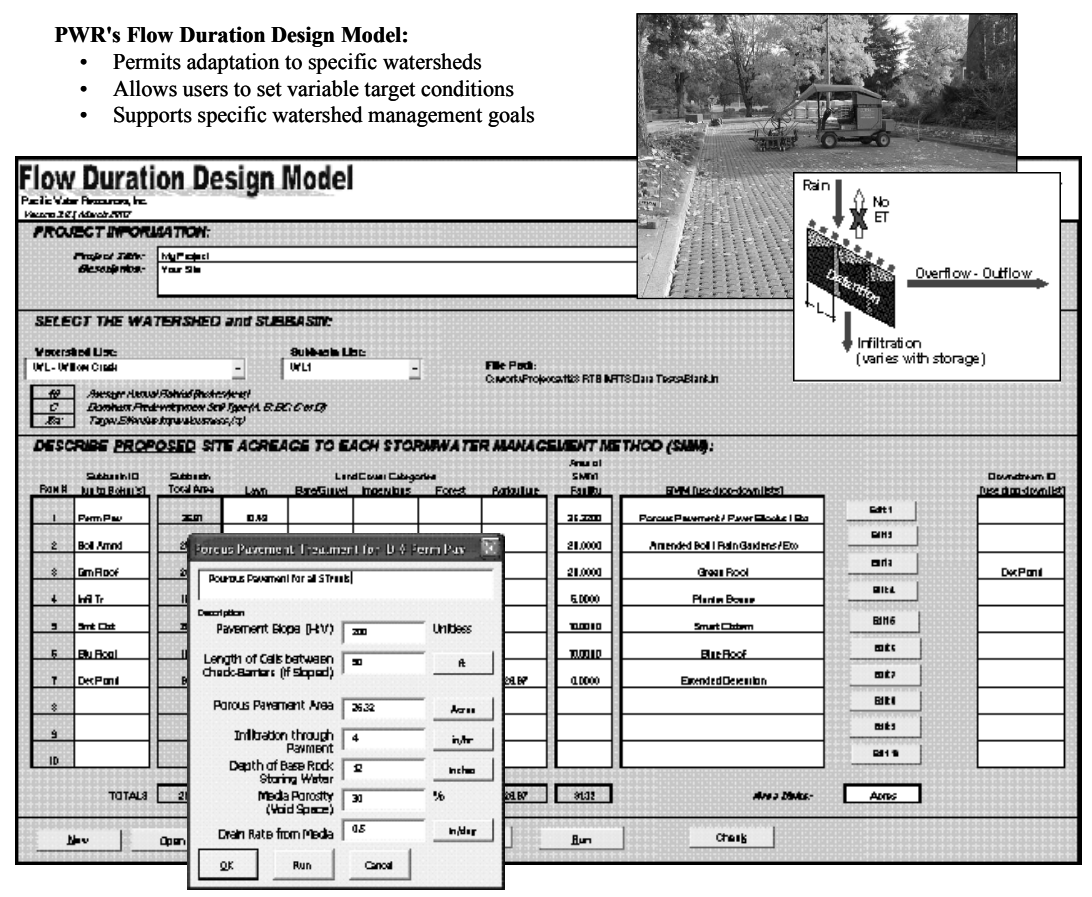

Figure 3.1 FDDM input screen with porous pavement design input parameters featured.

FDDM explicitly models several popular LID techniques for reducing runoff at the source. Currently, these include: porous pavement, amended soils, green roofs, blue roofs, planter boxes, infiltration trenches, smart cisterns and extended detention. Each LID simulation explicitly models the particular technique on an hour-by-hour basis considering inflow, storage, evaporation (if appropriate), infiltration and runoff. While FDDM can model several LID techniques at once, the tool also allows users to optimize individual LID designs. 
Continuous multi-year hydrographs that FDDM produces allow statistical comparisons of flow durations under both targeted and proposed conditions. Flow durations represent the fraction of time that a given flow is exceeded, and serve to quantify the effects (on a site basis) of proposed changes to basin hydrology. The tool presents flow durations for both proposed and targeted conditions graphically; allowing designers to quickly compare the proposed conditions that reflect the current design versus the targeted conditions that must be achieved (see Figure 3.2).

The lower-limit flow on the flow duration curves shown on Figure 3.2 has been set at the estimated one-half of the $2 \mathrm{y}$ peak discharge for the targeted imperviousness. This is done because it is not desirable to require that site design flows match a target flow below this geomorphically important threshold. A high-limit flow is also set because hydrologic analyses have repeatedly shown that at some point extreme flood flows are so rare and brief that it is neither practical nor cost-effective to require their reduction, especially at a site level. The high-limit flow could vary depending on watershed conditions and whether regional detention or other forms of flood control currently exist. In Figure 3.2, the high-limit flow is based on the $10 \mathrm{y}$ return interval peak discharged expected under the targeted imperviousness.

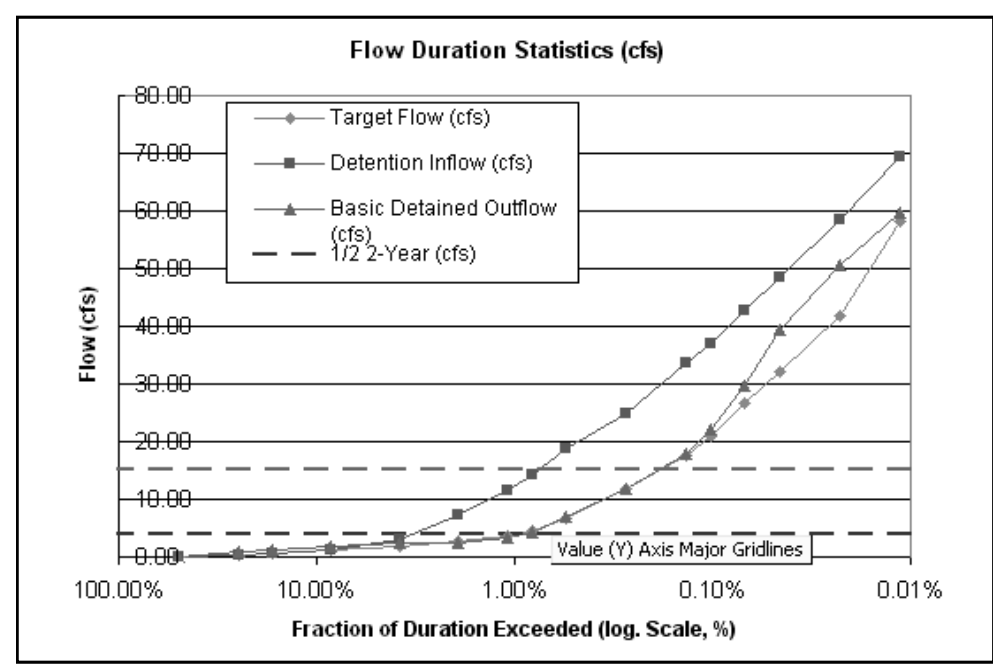

Figure 3.2 FDDM output showing target flows and design flows for LID practices specified. 
Each LID element is characterized with its own distribution of contributing land surfaces discharging either offsite or to another treatment option downstream. Cascading treatments allow designers significant flexibility, which will lead to an explicit understanding of the pollutant reduction effectiveness of "treatment trains" once these capabilities are added to create an expanded stormwater management tool as described in the next section.

\subsection{Pollutant Reduction Spreadsheet Tool (PreST)}

The stormwater management tool we envision will have the ability to explicitly model the pollutant reduction effectiveness of both structural and non-structural BMPs. In April 2004, the authors proposed the development of a comprehensive stormwater quality management model called the Pollutant Reduction Spreadsheet Tool (PReST) to the Oregon Association of Clean Water Agencies (ACWA). Figure 3.3 displays the basic elements of this tool shown within the circle. PReST's outputs are estimates of specific pollutant loadings and concentrations entering receiving waters along with the pollutant removal from specified BMPs with their marginal costs also computed and shown.

Development of PReST was not funded and ACWA chose instead to use the existing PLOAD model, one of the "simple method" approaches discussed previously. Ultimately, several ACWA members were disappointed with the project's results in that assigning pollutant concentrations to each type of land use provided no direct linkage or understanding of how site-level management actions could actually affect stormwater quality. Like any stormwater tool based on any "simple method" approach, PLOAD is not designed to evaluate the explicit interaction of multiple BMPs, such as street and catchbasin cleaning, end of pipe treatment, LIDs, and extended detention.

Four out of the five PReST model components shown in Figure 3.3 already exist in other models developed by PWR and would only need to be integrated together. Components $\mathrm{A}$ and $\mathrm{C}$ would be based on the existing Simplified Particulate Transport Model (SIMPTM) developed by Sutherland and Jelen (1998). SIMPTM was originally developed in the early 1980s and has been used numerous times with continual improvements for over almost three decades. The model is currently at Version 5.0 with the publication of the Version 5.0 Release Notes associated with the completion of the Cross Israel Highway Stormwater Quality Study in 2004 (Sutherland et al., 2006). 


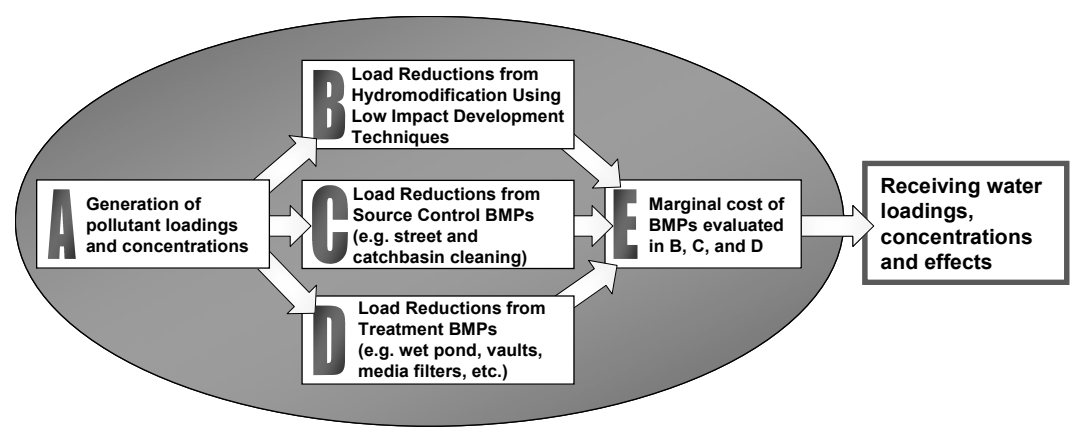

Figure 3.3 Pollutant reduction spreadsheet tool (PreST) components.

SIMPTM can explicitly simulate the physical processes of build up, washon and washoff linking actual site characteristics to storm-by-storm pollutant loadings and concentrations. SIMPTM also includes algorithms for sediment trapping in catchbasins and can simulate the explicit removal of sediments and associated pollutants as a result of both catchbasin and street cleaning practices. Associations between transported or captured particulate fractions and other pollutants of interest already exist.

Many would likely recommended the use of EPA-SWMM 5.0 to fulfill the requirements of Components $\mathrm{A}$ and $\mathrm{C}$. Unfortunately, the stormwater quality routines in SWMM have numerous problems that significantly affect their ability to accurately simulate pollutant loadings and concentrations. Please refer to Sutherland and Jelen (2002) for a complete documentation of the shortcomings of the existing SWMM's routines. (When the 2002 SWMM paper was written, there was still some hope that the recommended SIMPTM algorithms would be included in the EPA-SWMM Version 5.0 upgrades. Unfortunately, this did not occur so the existing SWMM 5.0 has the same stormwater quality problems as its predecessor Version 4.3).

Since the washoff algorithms in SIMPTM are sediment transport based, they will provide a much greater understanding of the incoming stormwater characteristics that can significantly affect the design of treatment BMPs (i.e. Component D). This is the only component of PReST that has not been developed.

Component B could be based on the structure and algorithms in FDDM, as described previously. The stormwater management tool we envision would have the capabilities of PReST but with a site based look and structure similar to FDDM. The focus would be the specific hydrologic and pollutant loading response of a proposed development site. However, the 
ability to vary targeted imperviousness by subbasin throughout any complex watershed where the tool may be implemented affords the local jurisdiction the opportunity to ensure watershed based goals are still being met as part of the development of a single site.

As stated previously, Component $\mathrm{D}$ would be new and would involve the development of algorithms to estimate load reductions from treatment BMPs such as gravity separation or media filtration devices. Considering that the simulated input to the treatment BMP algorithms will be a continuous trace of flow, pollutant concentration, and particle size distribution for the transported sediment fraction, even the most simplistic sediment and pollutant removal equations are likely to yield considerable benefits. And, SIMPTM already includes tested and proven catchbasin sediment trapping routines.

Component $\mathrm{E}$ could be based on the work completed by the primary author and his colleague Seth Jelen that has been used to compute the marginal costs of street cleaning practices (Sutherland and Jelen, 1997; Sutherland et al., 2001). Heaney and Nix (1977) originally developed the marginal cost algorithms that are proposed for use by PReST. These algorithms were designed to obtain the optimum combination of cost effective BMPs needed to achieve a specific pollutant reduction.

In addition to the flow duration curves output by FDDM, PReST would also provide both concentration duration and load duration curves for specific pollutants of interest. These curves could tell users how often pollutant concentrations based on water quality standards, for example, would be exceeded during wet weather discharges from the modeled site. Or, in the case of loadings, these curves could tell them how often some established TMDL would be exceeded. This could eventually lead to development of more realistic and practical wet weather water quality standards and TMDLs that recognize the infrequent occurrences of high pollutant concentrations and loadings, a positive outcome of this new modeling approach.

PReST, if created, will provide the user with the opportunity to understand the differences in pollutant concentrations and loadings due to differences in site characteristics. For example, dry weather pollutant build up on impervious surfaces could be a function of traffic volume and pavement characteristics. Wet weather washon would be explicitly simulated as transported sediments from adjacent areas that are deposited on directly connected impervious areas during recession flows. The pick-up or removal of accumulated sediments from pavement cleaning would be simulated as a function of sediment accumulations, particle size distributions and sweeper 
pick-up performance, which is tied to actual testing, as it is in SIMPTM today (Sutherland and Jelen, 1997).

\subsection{Focus Future Data Collection Efforts}

The development and use of physically based explicit models will provide a better understanding of the stormwater quality data we already have collected. Much work has already been completed towards this goal but more is needed. Once the PReST model has been assembled, it can be used to conduct case studies of sites were previous stormwater quantity and quality data collection has occurred. The results from these case studies would then focus needed attention on developing a better understanding of the physical processes that lead to the production of contaminated stormwater. New data collection efforts could focus on:

1. Sample the particulate material accumulation on the street or parking lot directly, rather than (or in addition to) stormwater runoff. Measure the street dirt on the pavement before and after storms. The difference is what was removed with stormwater, assuming washon from adjacent areas has been excluded by proper site selection. The procedure is safer and less costly than sampling stormwater. Such sampling provides a rapid cost-effective characterization for correlating levels of parking lot and streets use and eventual stormwater quality.

2. Sample precipitation quality (i.e. wet deposition) for pollutants of interest at significant concentrations and not washed from impervious surfaces. This provides better information regarding the effectiveness of some BMPs, and the origin of some pollutants.

3. Consider the significance of air emissions from industries. Deposition occurs on water bodies and impervious surfaces, both directly and indirectly. Items \#1, 2 and 3 allow better decisions regarding the benefits of air pollution controls and pavement cleaning.

4. Studies over the past 40 years have shown that fecal coliform is a meaningless indicator of the presence or absence of disease organisms. Enterococci and E. coli have been shown to be better indicators. Consider using these 
indicators and sampling swimming beaches and surveying gastrointestinal illnesses, rather then general bacti characterizations.

5. Characterize stormwater quality by toxicity, rather than "laundry lists" of pollutants. Where toxicity is observed, specialized studies can then focus on causes. Dissolved pollutants are not necessarily bioavailable due to the complexities of stormwater chemistry. Inferring potential or presumed toxicity by comparing concentrations of metals, $\mathrm{PAH}$, and/or pesticides, to esoteric receiving-water standards is likely misleading.

As more data in each of these interest areas is collected, further model refinements can be made. It is through this continuing iterative process that we will improve our understanding of stormwater quality and our ability to effectively change the stormwater quality response through our BMP selection and design.

\subsection{Closing Comments}

Ideas have been offered on how we could leverage decades of work developing and refining SIMPTM and more recent efforts used to produce FDDM to create an explicit and scientifically based stormwater management model called the Pollutant Reduction Spreadsheet Tool (PReST). PReST would be easy to use and have the look and feel of a simple EXCEL spreadsheet. But it would function instead as a powerful simulation model providing the user with quick and accurate results. PReST could be used to design the appropriate LIDs, BMPs, and cleaning or maintenance practices for a specific development site within a watershed in a manner that ensures an overall watershed management strategy is being implemented. Four of the five major components envisioned for this powerful modeling tool already exist today and are ready for integration into one single program.

Imagine a stormwater management tool that can accurately estimate the flows, pollutant concentrations and loadings being discharged from a specific site within a given watershed. Imagine a management tool that can accurately estimate the flow and pollutant reduction effectiveness of a site specific development proposal, not for just a single storm or a series of storms but for a period of time equivalent to the longest historical record of precipitation available within the region. Imagine the ability to understand 
how cost effective a specific stormwater management practice is in the removal of a specific pollutant at a specific location in a specific watershed. Imagine the ability to understand how the implementation of a single BMP or multiple BMPs could affect not only the mean or median concentrations of a given pollutant but the actual distribution of the entire population of concentrations that would have occurred throughout the historical rainfall record. Imagine the ability to understand the variation in pollutant loadings and concentrations that result from differences in traffic volume, pavement condition, site imperviousness and other important site characteristics. Imagine a tool that can be used equally well in both the evaluation of a new development or a retrofit of an existing area.

The technology now exists along with the algorithms that have been tested and have proven to accurately reproduce real data. Almost all of the pieces to this complex stormwater quality modeling puzzle now exist. The missing component is the financial resources needed to finally assemble these pieces so that the stormwater communities that many of us serve can finally get some answers to the very important questions surrounding urban stormwater pollution.

\section{References}

Heaney, J.P., and S.J. Nix, (1977). "Stormwater Management Model: Level I Comparative Evaluation of Storage-Treatment and Other Management Practices". EPA-600/2-77-083.

Kim, J.Y., and J.J. Sansalone, (2008). "Event-Based Size Distributions of Particulate Matter Transported During Urban Rainfall-Runoff Events". (Manuscript In Press).

Maestre, A. and R.E. Pitt. 2007. "Stormwater Databases: NURP, USGS, International BMP Database and NSQD." Journal of Water Management Modeling R227-20. doi: 10.14796/JWMM.R227-20.

Minton, G.R. (2002). Stormwater Treatment: Biological, Chemical, and Engineering Principles, Resource Planning Associates, Seattle, WA. (http://www.stormwaterbook.com)

Pitt, R.E. 1997. "Unique Features of the Source Loading and Management Model (SLAMM)." Journal of Water Management Modeling R200-02. doi: 10.14796/JWMM.R200-02.

Pitt, R.E., R. Bannerman, S. Clark and D. Williamson. 2005. "Sources of Pollutants in Urban Areas (Part 1) - Older Monitoring." Journal of Water Management Modeling R223-23. doi: 10.14796/JWMM.R223-23.

Pitt, R.E. and J. Voorhees (1995). "Source Loading and Management Model (SLAMM)". Seminar Publication: National Conference on Urban Runoff Management: 
Enhancing Urban Watershed Management at the Local, County and State Levels. March 30-April 2, 199"3. Grant No. EPA/625/R-95/003. U.S. Environmental Protection Agency. Center for Environmental Research Information. Cincinnati, OH: 225-243.

Sansalone, J.J., and C.M. Cristina, (2004). "Prediction of Gradation-Based Heavy Metal Mass Using Granulometric Indices of Snowmelt Particles". In: Journal of Environmental Engineering. ASCE. 130(12): 1488-1497.

Sansalone, J.J., J.M. Koran, J.A. Smithson, and S.G. Buchberger, (1998). "Physical Characteristics of Urban Roadway Solids Transported During Rain Events". In: Journal of Environmental Engineering. ASCE. 124(5): 348-365.

Shaheen, D.G. (1975). "Contributions of Urban Roadway Usage to Water Pollution," U.S. Environmental Protection Agency, EPA-600/2-75-004.

Sutherland, R. and S.L. Jelen. 1996. "Sophisticated Stormwater Quality Modeling is Worth the Effort." Journal of Water Management Modeling R191-01. doi: 10.14796/JWMM.R191-01.

Sutherland, R. and S.L. Jelen. 1997. "Contrary to Conventional Wisdom, Street Sweeping Can be an Effective BMP." Journal of Water Management Modeling R195-09. doi: 10.14796/JWMM.R195-09.

Sutherland, R.C., and S.L. Jelen (1998). Simplified Particulate Transport Model User's Manual, Version 3.2. Pacific Water Resources, Inc., Beaverton, Oregon.

Sutherland, R. and S.L. Jelen. 2002. "Stormwater Quality Modeling Improvements Needed for SWMM." Journal of Water Management Modeling R215-13. doi: 10.14796/JWMM.R215-13.

Sutherland, R., R. Myllyoja and S.L. Jelen. 2001. "Quantifying the Stormwater Pollutant Reduction Benefits of Traditional Public Works Maintenance Practices." Journal of Water Management Modeling R208-09. doi: 10.14796/JWMM.R208-09.

Sutherland, R., G.R. Minton and U. Marinov. 2006. "Stormwater Quality Modeling of Cross Israel Highway Runoff." Journal of Water Management Modeling R225-08. doi: 10.14796/JWMM.R225-08.

Waschbusch, R.J., W.R. Selbig, and R.T. Bannerman (1999). "Sources of Phosphorus in Stormwater and Street Dirt from Two Urban Residential Basins in Madison, Wisconsin, 1994-1995”. U.S. Geological Survey, Middleton, Wisconsin, Water Resource Investigations Report 99-4021. 